\title{
RETRACTED ARTICLE: A Measurement Approach Using Smart-loT Based Architecture for Detecting the COVID-19
}

\author{
Poongodi M. ${ }^{1} \cdot$ Tu N. Nguyen ${ }^{2} \cdot$ Mounir Hamdi $^{1} \cdot$ Korhan Cengiz $^{3}$
}

Accepted: 19 July 2021 / Published online: 4 August 2021

(c) The Author(s), under exclusive licence to Springer Science+Business Media, LLC, part of Springer Nature 2021

The Editor-in-Chief and the publisher have retracted this article. The article was submitted to be part of a guest-edited issue. An investigation by the publisher found a number of articles, including this one, with a number of concerns, including but not limited to compromised editorial handling and peer review process, inappropriate or irrelevant references or not being in scope of the journal or guest-edited issue. Based on the investigation's findings the Editorin-Chief therefore no longer has confidence in the results and conclusions of this article. The authors Poongodi M., Tu N. Nguyen and Korhan Cengiz disagree with this retraction. The Author Mounir Hamdi has not responded to correspondence regarding this retraction. The online version of this article contains the full text of the retracted article as Supplementary Information.

Supplementary Information The online version contains supplementary material available at https://doi. org/10.1007/s11063-021-10602-x.

Publisher's Note Springer Nature remains neutral with regard to jurisdictional claims in published maps and institutional affiliations.

Korhan Cengiz

korhancengiz@trakya.edu.tr

Poongodi M.

dr.m.poongodi@gmail.com

Tu N. Nguyen

tu.nguyen@kennesaw.edu

Mounir Hamdi

mhamdi@hbku.edu.qa

1 College of Science of Engineering, Hamad Bin Khalifa University, Doha, Qatar

2 Department of Computer Science, Kennesaw State University, Marietta, GA 30060, USA

3 Department of Electrical - Electronics Engineering, Trakya University, 22030 Edirne, Turkey 